\title{
Preparation of Ag-Cu Composite Nanoparticles by the Submerged Arc Discharge Method in Aqueous Media
}

\author{
Kuo-Hsiung Tseng*, Chih-Ju Chou, To-Cheng Liu, Yu-Han Haung and Meng-Yun Chung \\ Department of Electrical Engineering, National Taipei University of Technology, Taipei 10608, Taiwan, R.O.C.
}

\begin{abstract}
For this study, electrical discharge machining (EDM) and the submerged arc discharge method (SADM) were used to melt a silver-copper composite metal in deionized water through concentrated arc energy in order to produce metal fluids containing nano- and submicron particles. The fabrication process did not require additional chemicals, and was simple and efficient. The critical processing parameters for EDM were the discharge voltage and current as well as the on-off duration for pulse discharge; the sample concentration could be controlled under appropriate conditions. The experimental results revealed that, through electronic system design and manufacturing (ESDM), silver-copper composite metal particles could be achieved at a nano to submicron level. In addition, the results obtained varied according to differences in the on-off duration regarding pulse discharge. In this study, when the discharging parameter $\left(T_{\mathrm{on}}-T_{\mathrm{off}}\right)$ was at $30: 50$, nanocomposite fluids with an optimal concentration and small particles were obtained. The application of EADM could enable the mass production of composite metal fluids or particles at low cost and high efficiency. Employing EADM for the fabrication of composite metal fluids or particles warrants research attention, and the process itself can be developed further. [doi:10.2320/matertrans.M2015288]
\end{abstract}

(Received July 13, 2015; Accepted December 24, 2015; Published February 25, 2016)

Keywords: electric discharge machining, electric spark discharge method, nano composite fluid, electric capacity charge

\section{Introduction}

$\mathrm{Ag}$ and $\mathrm{Cu}$ are highly conductive metals. $\mathrm{Ag}$ and $\mathrm{Cu}$ nanomaterials have been widely employed in numerous areas (e.g., medicine, catalysis, ${ }^{1,2)}$ chemical engineering, sensors, ${ }^{3)}$ optical and biological devices, ${ }^{4-7)}$ and in the electronics industry. ${ }^{8-10)}$ Turkevich was the first person to fabricate bimetallic nanoparticles with a core-shell structure. Turkevich first fabricated core-shaped metal nanoparticles through homogeneous nucleation. He subsequently used the second type of metal ions to coat the core-shaped metal particles through inhomogeneous nucleation, thereby obtaining a core-shell bimetallic structure.

Numerous researchers have employed various methods in their study of nanocomposite metal fluids. The following are examples: Toshima applied the alcohol reduction method to fabricate copper-palladium, copper-platinum, and gold-palladium bimetallic nanoparticles. ${ }^{11,12}$ El-Sayed employed the synchronous reduction method to extract gold and silver ions from sodium citrate, and to produce gold-silver alloy nanoparticles. ${ }^{13)}$ Natan was the first person to fabricate gold nanoparticles, before adding silver salts to the gold nanoparticle solution in order to obtain a silver coating on the surface of the gold particles, thus producing bimetallic particles characterized by a gold core and a silver shell. ${ }^{14)}$ Mizukoshi and Nagata adopted an ultrasonic resonance method to obtain gold-palladium core-shell nanoparticles. ${ }^{15)}$ Delcourt employed a photochemical method to produce goldplatinum and silver-platinum bimetallic nanoparticles. ${ }^{16)}$ By contrast, Chen utilized the microemulsion method to obtain gold-silver bimetallic nanoparticles. $\left.{ }^{17}\right)$ Yeh applied laser irradiation to obtain gold-silver alloy nanoparticles from a mixture solution composed of gold and silver nanoparticles. ${ }^{18)}$ Kim submerged a gold-silver alloy metal sheet into an aqueous solution before applying a laser on the metal sheet, thereby yielding gold-silver alloy nanoparticles. ${ }^{19)}$

*Corresponding author, E-mail: khtseng@ee.ntut.edu.tw
Nakamura employed the chemical reduction method to obtain silver-copper composite nanoparticles, ${ }^{20)}$ whereas Esumi utilized the reduction method to produce silverpalladium alloy nanoparticles. ${ }^{21)}$ Henglein adopted the radiation-reduction method to achieve bimetallic nanoparticles with a palladium core and a silver shell. ${ }^{22)}$ Tseng employed electrical discharge machining (EDM) and the submerged arc discharge method (SADM) to melt conductive metals into various types of nanometal colloids through concentrated arc energy (e.g., nanosilver, ${ }^{23}$ ) nanogold, ${ }^{24)}$ nanocopper, ${ }^{25)}$ and nanoaluminum, ${ }^{26)}$ and to explore the relationships between the characteristics of silver, copper, and titanium nanofluids and the EDM process parameters. ${ }^{27)}$

In this study, the SADM was employed to produce nanosilver-copper composite metal fluids (i.e., the positive electrode of a metal rod was silver, and the negative electrode was copper; both electrodes were submerged in dielectric fluid). A switch knob was used for polarity control; the polarity was adjusted every $30 \mathrm{~s}$ to reduce the weight of silver and copper considerably, so that similar concentrations of both could be obtained. During the production process, when the gap between the positive and the negative electrodes of a material became sufficiently small, electric arc discharging (plasma) ${ }^{28)}$ occurred, followed by heating, which reached a high temperature of 1500 to $5000 \mathrm{~K}$. Silver and copper particles were produced at a high temperature because of ionization occurring on the surface of the electrodes, and after cooling in the dielectric fluid, the nanosilver-copper composite metal fluids were obtained.

\section{Experimental Setup}

The submerged arc discharge method used in this study consists of (1) The servo control system which can control the distance between the gap; (2) the power supply system which can modify arc discharge parameters; (3) the isothermal system provide constant temperature. The SADM took the usage of the high temperature which was produced 


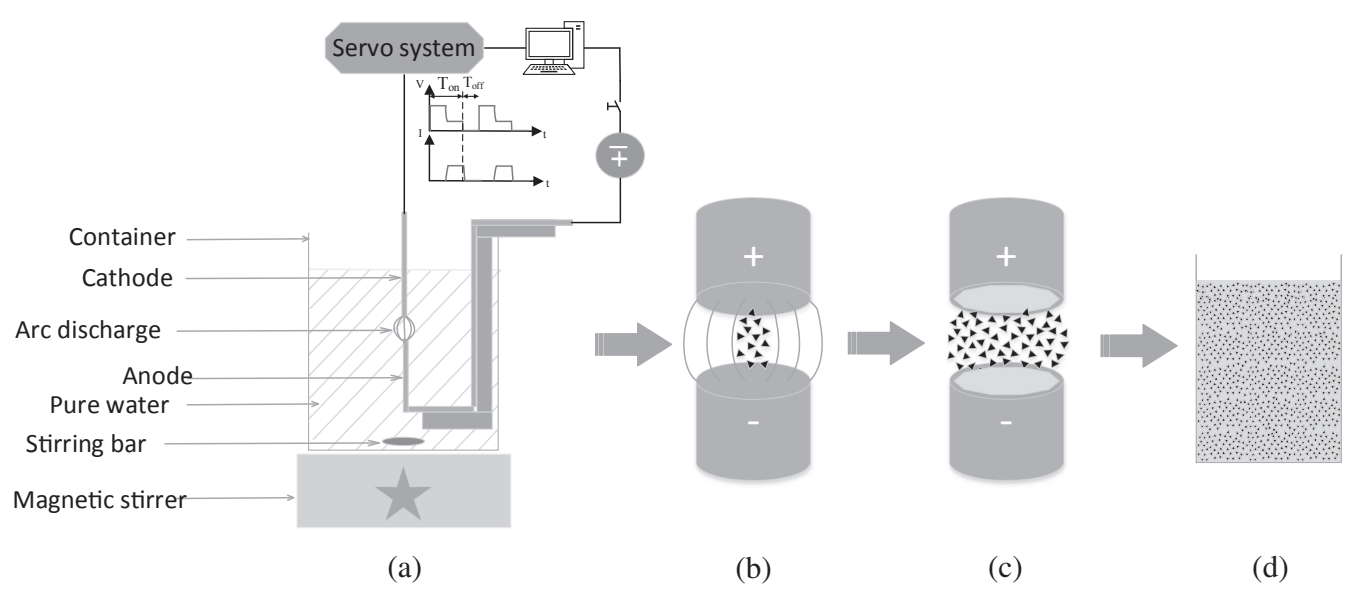

Fig. 1 Diagram of submerged arc discharge method (SADM) system. (a) SADM system configuration, (b) Ionization and cathode emit electrons, (c) Metal bursts out, (d) Metal particle suspended or precipitated in the dielectric liquid.

by the arc to melt the surface of the anode. Simultaneously, the arc column impact the electrode in the dielectric fluid and stirred away from the electrodes. The gap between the electrodes became insulation again. The process of the SADM is shown in Fig. 1.

\subsection{Materials and preparation}

Figure 1(a) displays the SADM system. As shown in the figure, the silver and copper wires (purity: 99.99\%) had a diameter of $1 \mathrm{~mm}$. They served as the anode and cathode, respectively, and were submerged in deionized water (Milli-Q, $18.2 \mathrm{M} \Omega \cdot \mathrm{cm})$ or in $95 \%$ ethanol $(\mathrm{EtOH})$. The servo system made appropriate adjustments consistently regarding the distance between the two electrodes during the discharging process in order to trigger an arc discharge (plasma) at the tip of both electrodes submerged in the dielectric fluid. The gap between the two electrodes was regulated at approximately $30 \mu \mathrm{m}$, as shown in Fig. 1(b). After the arc discharge occurred for the on-duration, the metal particles sputtered onto the electrode surface, as shown in Fig. 1(c). The two electrodes subsequently became isolated for the off-duration, until the next discharging cycle. A stirring bar and a magnetic stirrer were installed at the bottom of a collection tank. During the discharging process, the metal particles were stirred until they were evenly distributed in the dielectric fluid, as shown in Fig. 1(d).

Configuring process parameters of silver-copper composite metal fluid. For the experiment, silver and copper wires with a diameter of $1 \mathrm{~mm}$ were used. According to the experimental conditions regarding the preparation parameters for silver and copper, when $T_{\text {on }}$ was lower than $T_{\text {off, }}$ the preparation efficiency for the nanofluid was optimal. Accordingly, Table 1 shows the preparation parameters of the alloy, and the condition under which $T_{\text {on }}$ was greater than $T_{\text {off }}$ was not considered.

\subsection{Analysis equipment}

In this study, deionized water and (EtOH) were used as a medium liquid to produce silver and copper particles. Regarding the particle surface, a scanning electron microscope (SEM) and energy-dispersive X-ray spectroscopy (EDX) were used to analyze the proportion of elements in
Table 1 Parametric values for the discharging control panel to fabricate nanocomposite metal fluids.

\begin{tabular}{ll}
\hline \multicolumn{1}{c}{ Parameter settings for Ag-Cu composite fluids } \\
\hline$I_{\mathrm{P}}$ & 1 \\
Voltage & $140 \mathrm{~V}$ \\
Capacity & Off \\
Z-axis knob & Off \\
Sensitivity knob & $1 / 2$ \\
Servo knob & $1 / 2$ \\
Temperature & $25^{\circ} \mathrm{C}$ \\
Volumn & $25 \mathrm{ml}$ \\
Discharge time & $5 \mathrm{~min}$ \\
Dielectric fluids & Pure water \\
Purity of metal & $99.99 \%$ \\
Diameter & $1 \mathrm{~mm}$ \\
$T_{\text {on }} T_{\text {off }}$ & $10 \sim 150 \mu \mathrm{s}$ \\
Atmospheric pressure & $1 \mathrm{~atm}$ \\
\hline
\end{tabular}

the samples, and to identify the material composition of the samples fabricated employing the SADM. The X-ray diffraction method was adopted to analyze the lattice structure of the samples. In addition, a Zetasizer nanosystem was employed to examine how the distribution of the particle diameter as well as the surface potential of the silver and copper particles affect suspension stability, and to observe the particles in various dielectric fluids.

\subsection{Applying the capacitor charging method to improve zeta potential in metal nanoparticles}

In this experiment, the SADM was employed. For this method, deionized water, EtOH, and a silver-copper rod were used to produce silver-copper nano-composite metal fluids without adding chemicals. After the fabrication, the color of it is black and the particle can be seen at the bottom of the fluid. The experimental results revealed that the interfacial potential of the silver-copper nano-composite metal fluids was extremely small; after a certain period, the interfacial potential approximated $0 \mathrm{mV}$, and the nanoparticles precipitated to the bottom of the container. Because the zeta potential was extremely small, the particles became precip- 


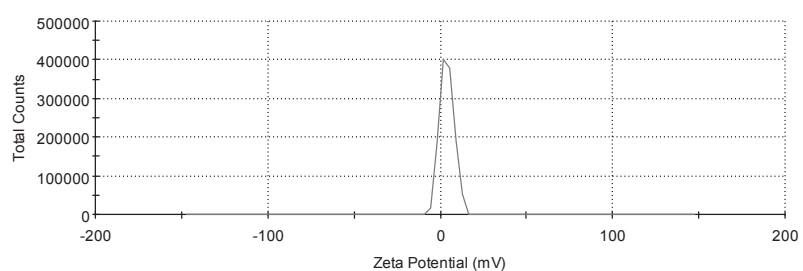

Fig. 2 Zeta potential of silver-copper composite fluid.

(a)

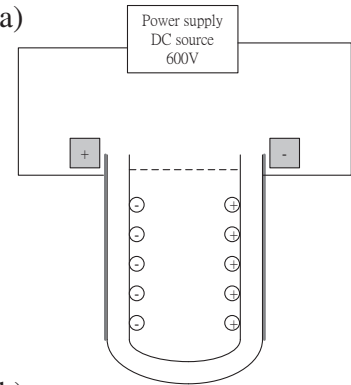

(b)

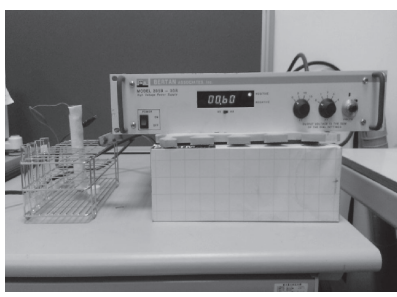

Fig. 3 (a) Schematic diagram, (b) physical diagram for the experimental design of zeta-potential improvement.

itates after a short period, as shown in Fig. 2. In this study, the capacitor charging method was used to charge nanofluid. In addition, electric energy was employed to stimulate the characteristics of free electrons, and to examine whether the zeta potential of the nanoparticles could be raised, as shown in Fig. 3. In accordance with the capacitance principle, two pieces of copper foil were affixed to a burette and used as the positive and negative electrodes of a capacitor. The two electrodes were connected to a $600-\mathrm{V}$ power supply unit. The wall of the burette and the silver-copper nanocomposite fluid were used as the dielectric material, the structure of which acted as a capacitor. Because of the polarity of the zeta potential, attraction or repulsion occurred between the nanoparticles and the inner wall of the burette. Charged ions in the medium liquid were also affected, thereby permitting an examination of any improvements in the suspension stability of the nanoparticles.

\section{Results and Discussion}

\subsection{Fabricating silver-copper alloy nanoparticles}

According to the parameter in Table 1, nanocomposite silver-copper fluid is fabricated. For structural equation modeling (SEM) analysis, a carbon film was used as a carrier. Oxygen typically accompanied the carbon film, and therefore, $\mathrm{C}$ and $\mathrm{O}$ were present, according to energydispersive X-ray spectroscopy (EDX) analysis. Table 2, Figures 4 and 5 display the EDX analysis results. The SEM diagram illustrates the SADM application for the
Table 2 EDX application for the analysis of the proportions of elements in silver-copper alloy.

\begin{tabular}{ccc}
\hline Element & mass $(\%)$ & Atomic $(\%)$ \\
\hline $\mathrm{C}$ & 78.39 & 83.84 \\
$\mathrm{O}$ & 19.77 & 15.87 \\
$\mathrm{Cu}$ & 0.83 & 0.17 \\
$\mathrm{Ag}$ & 1.01 & 0.12 \\
\hline
\end{tabular}

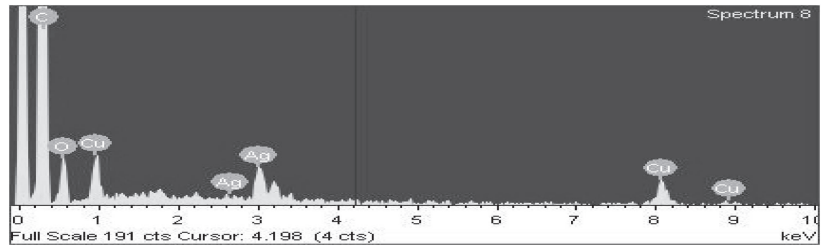

Fig. 4 An EDX diagram.

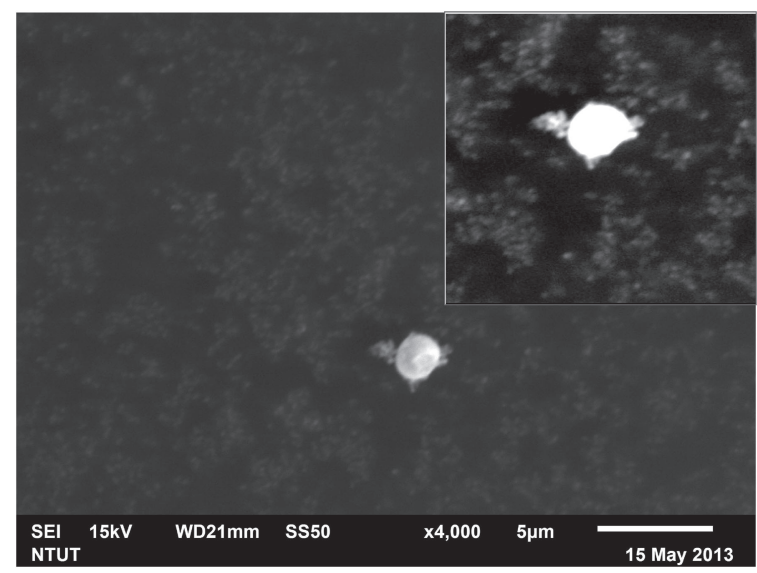

Fig. 5 An SEM diagram of silver-copper alloy particles.

production of alloy nanoparticles. Take $\mathrm{Ag}$ as example, $0.12 \%$ means that there are about $0.12 \%$ of $\mathrm{Ag}$ in the sample. As shown in Fig. 5, a circular particle contained another circular particle, and thus, the samples fabricated for this study were core-shell alloy nanoparticles.

\section{2 $T_{0 \mathrm{n}}-T_{\text {off }}$ analysis for silver-copper composite fluids}

As described, regarding the optimal parameters for the production of silver-copper nanocomposite metal fluids, $T_{\text {on }}$ for silver and copper must be smaller than $T_{\text {off }}$ in order to obtain satisfactory parameters. Therefore, in the experiment, $T_{\text {on }}$ must be set to be smaller than $T_{\text {off }}$, so that the parameters can be compared under various ratios. The details are as follows:

\subsection{1 $T_{\text {on }}-T_{\text {off }}$ analysis for silver-copper composite fluids with equal proportions of silver and copper}

(a) $T_{\text {on }}-T_{\text {off }}$ analysis for silver-copper composite fluids with equal proportions of silver and copper. During the fabrication of the nanocomposite metals, a knob was required to adjust the polarity and to equalize the mass loss for both silver and copper. If the mass loss ratio between silver and copper differed substantially, the proportion of the metal that lost more weight was higher in the fabricated alloy nanofluid. When a metal that lost 
Table 3 Mass loss of positive and negative electrodes for identical $T_{\mathrm{on}}-T_{\text {off }}$ proportion.

\begin{tabular}{|c|c|c|c|c|c|}
\hline \multirow{2}{*}{$\begin{array}{l}I_{\mathrm{P}}=1 ; \\
\text { Processing time: } 5 \mathrm{~min}\end{array}$} & \multicolumn{5}{|c|}{$T_{\text {on }}-T_{\text {off }}$ (unit: $\left.\mu \mathrm{s}\right)$} \\
\hline & $10: 10$ & $30: 30$ & $50: 50$ & $100: 100$ & $150: 150$ \\
\hline Mass loss of positive electrode (Ag) (mg) & 0.5 & 0.4 & 0.6 & 0.6 & 0.5 \\
\hline Mass difference of two poles (mg) & 0.3 & 0.2 & 0.3 & 0.2 & 0.2 \\
\hline Total mass loss (mg) & 0.7 & 0.6 & 0.9 & 1.0 & 0.8 \\
\hline
\end{tabular}

Table 4 Particle size and zeta potential for equal ratios of silver to copper.

\begin{tabular}{lcccc}
\hline$I_{\mathrm{P}}=1 ;$ & & \multicolumn{2}{c}{$T_{\text {on }}-T_{\text {off }}$ (unit: $\left.\mu \mathrm{s}\right)$} \\
Processing time: $5 \mathrm{~min}$ & $10: 10$ & $30: 30$ & $50: 50$ & $100: 100$ \\
\hline Intensity Size $(\mathrm{nm})$ & 147.7 & 171 & 171 & 265 \\
Total Counts zeta potential $(\mathrm{mV})$ & 16.5 & 13.1 & 12.2 & 150 \\
\hline
\end{tabular}

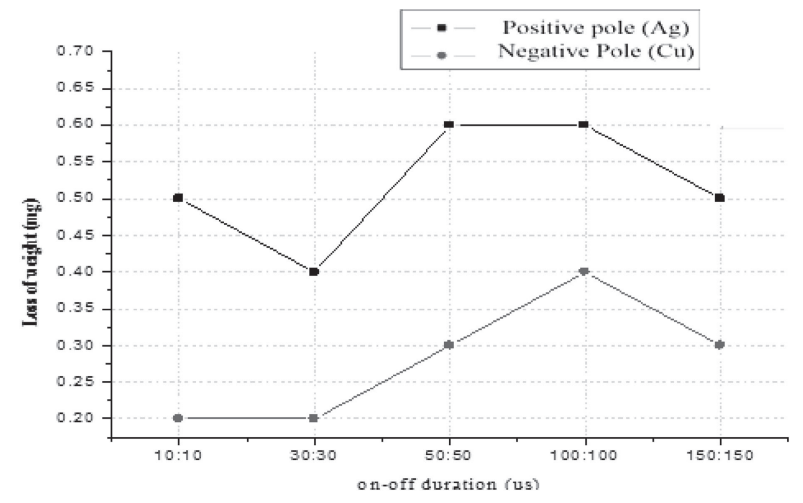

Fig. 6 Mass loss of silver-copper composite fluids with equal proportions of silver and copper.

more weight probably could not form alloy particles, it became condensed into single metal particles under pure water. As shown in Table 3 and Fig. 6, in this study, for $T_{\text {on }}-T_{\text {off }}$ analysis, the proportions of silver and copper in the silver-copper composite nanoparticles were set to be equal in order to observe the mass loss of the positive and negative electrodes, and to determine the optimal parameters for the nanocomposite metal fluids. $50: 50,100: 100$, and $150: 150$, the mass loss of the positive and negative electrodes was nearly identical. For the $100: 100$ ratio, the electrodes lost the most weight. Therefore, for that ratio, the success rate for discharging was relatively higher. In addition, more alloy nanoparticles were present in the fluid.

(b) As shown in Table 4, the particle size and zeta potential were compared under various silver and copper ratios. By the SADM, the mass loss is the most and the size of the particle is the biggest. As shown in Fig. 7, for the $100: 100$ ratio, the particle size was approximately $<200 \mathrm{~nm}$, which was also the maximum size. As shown in Fig. 8, for a ratio of $150: 150$, the zeta potential was smallest; for a ratio of $10: 10$, the particles were smallest, and the zeta potential was largest. Therefore, for equal ratios, a ratio of $10: 10$ was optimal.

Regarding the parameters of equal ratios, the results revealed that when $T_{\text {on }}-T_{\text {off }}=10: 10$, the particles were

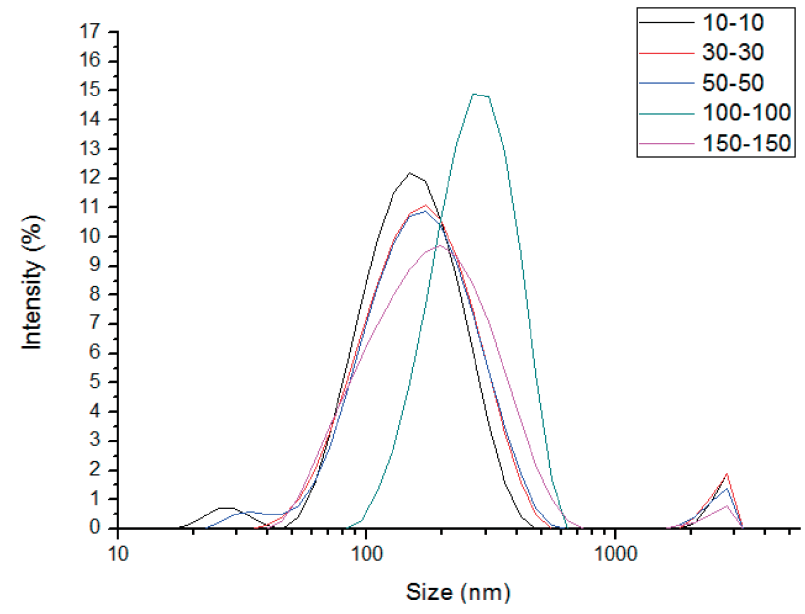

Fig. 7 Particle size for equal ratios of silver to copper.

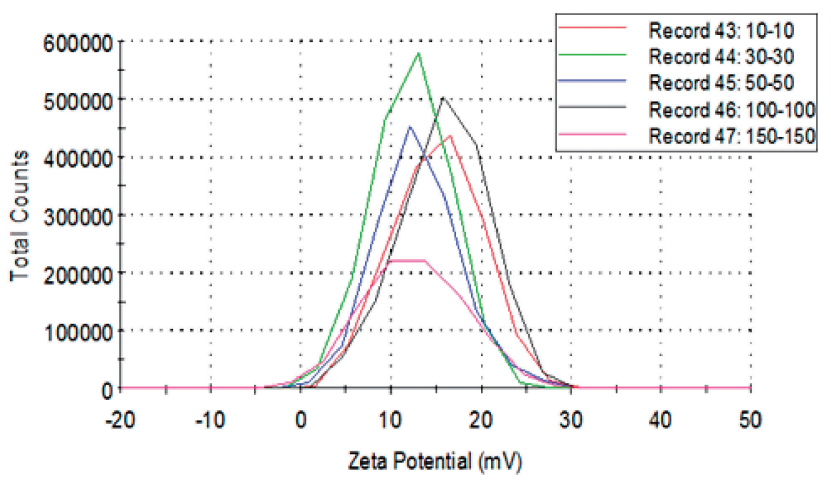

Fig. 8 Zeta-potential for equal ratios of silver to copper.

smallest, and the absolute value of the zeta potential was largest.

3.2.2 $T_{\text {on }}-T_{\text {off }}$ analysis for silver-copper composite fluids with unequal proportions of silver and copper

$T_{\text {on }}-T_{\text {off }}$ analysis for silver-copper composite fluids with unequal proportions of silver and copper. As shown in Table 5 and Fig. 9(a), regarding mass loss under unequal ratios of silver to copper, for a ratio of $10: 150$, the minimum difference between the two electrodes was noted. By contrast, ratios of $10: 50,10: 100,30: 50,30: 150$, and $50: 150$ 
Table 5 Mass loss of positive and negative electrodes for various $T_{\mathrm{on}}-T_{\text {off }}$ ratios, and particle size and zeta potential for various ratios.

\begin{tabular}{|c|c|c|c|c|c|c|}
\hline $\begin{array}{l}I_{\mathrm{P}}=1 \\
\text { Processing } \\
\text { time } 5 \mathrm{~min}\end{array}$ & $\begin{array}{l}\text { Mass loss } \\
\text { of positive } \\
\text { pole }(\mathrm{Ag})\end{array}$ & $\begin{array}{l}\text { Mass loss } \\
\text { of negative } \\
\text { pole }(\mathrm{Cu})\end{array}$ & $\begin{array}{l}\text { Mass difference of } \\
\text { two poles }\end{array}$ & Total mass loss & Intensity Size & $\begin{array}{l}\text { Total Counts } \\
\text { zeta potential }\end{array}$ \\
\hline us & $\mathrm{mg}$ & $\mathrm{mg}$ & $\mathrm{mg}$ & $\mathrm{mg}$ & $\mathrm{nm}$ & $\mathrm{mV}$ \\
\hline $10: 30$ & 0.6 & 0.3 & 0.3 & 0.9 & 171 & 19.7 \\
\hline $10: 50$ & 0.6 & 0.4 & 0.2 & 1.0 & 229 & 19.3 \\
\hline $10: 100$ & 0.6 & 0.4 & 0.2 & 1.0 & 147.7 & 17.3 \\
\hline $10: 150$ & 0.4 & 0.3 & 0.1 & 0.7 & 147.7 & 15.6 \\
\hline $30: 50$ & 0.6 & 0.4 & 0.2 & 1.0 & 127.5 & 15.5 \\
\hline $30: 100$ & 0.6 & 0.3 & 0.3 & 0.9 & 229.3 & 13.3 \\
\hline $30: 150$ & 0.6 & 0.4 & 0.2 & 1.0 & 171 & 14.2 \\
\hline $50: 100$ & 0.4 & 0.2 & 0.2 & 0.6 & 171 & 17.4 \\
\hline $50: 150$ & 0.6 & 0.4 & 0.2 & 1.0 & 198 & 15.8 \\
\hline $100: 150$ & 0.6 & 0.2 & 0.4 & 0.8 & 356 & 13 \\
\hline
\end{tabular}

resulted in maximum mass loss. With these five ratios, the highest discharge success rate was obtained for the silvercopper composite fluids. With ratios of $30: 100$ and $100: 150$, large particles and a small zeta potential were present. After the two ratios were eliminated, the particle size and zeta potential were compared for other ratios.

(a) In the Ratios of $10: 1010: 3010: 5010: 100$ and $10: 150$, the maximum size happened in $10: 50$. When $T_{\text {off }}$ is smaller than $50 \mu \mathrm{s}$, although the total time is longer, the time for the particle to defuse to the dielectric fluid is not enough. This is the reason that the number of silver-copper composite decreased. On the other hand, when $T_{\text {off }}$ is larger than $100 \mu \mathrm{s}, T_{\text {off }}$ is too long and the silver-copper composite number is low. The size of it is smaller than the case of $10: 50$. Figure 9(b) shows that $10: 100$ and in $10: 150$ is better.

(b) In the Ratios of $30: 3030: 5030: 100$ and $30: 150$, the maximum size happened in $30: 100$. When $T_{\text {off }}$ is smaller than $100 \mu \mathrm{s}$ (the cases of $30: 30$ and $30: 50$ ), although the total time is longer, the time for the particle to defuse to the dielectric fluid is not enough. This is the reason that the number of silver-copper composite decreased. On the other hand, when $T_{\text {off }}$ is larger than $100 \mu \mathrm{s}$ (the cases of $30: 150$ ), $T_{\text {off }}$ is too long and the silver-copper composite number is low. The size of it is smaller than the case of $10: 50$. Figure 9(c) shows that $30: 50$ is better.

(c) Compare the Table 4 and 5, when $T_{\text {on }}=50$ and $100 \mu \mathrm{s}$, the biggest size happened when $T_{\text {off }}$ is the longest. It is assume that during the melting, the time is not enough to make the composite to diffuse to the dielectric fluid. Therefore, the longer $T_{\text {off }}$ is, the bigger particle size is. And it is also assumed that the increase of the particle size will make the particle size smaller. Figure 9(d) shows that $50: 100$ is better.

(d) Among ratios of $10: 100,10: 150,30: 50$, and $50: 100$, the success rates of discharging for the ratios of $10: 100$ and $30: 50$ were relatively higher; by contrast, the particles obtained with the $30: 50$ ratio were smaller than those yielded with the ratio of $10: 100$. (e) In summary, when $T_{\text {on }}-T_{\text {off }}=30: 50$, the parameters were optimal.

For parameters with unequal ratios, the amount of total mass loss was used to infer the success rate of discharging for the samples, and to select the sets with the maximum mass loss. Because of the high success rate of discharging, the material removal rate was high. After the sets with high success rates for discharging were selected, the particle size was referred to in order to identify sets with small particles. Because of minor differences in the absolute value of the zeta potential among the various parameters, the parameter with the smallest zeta potential was removed, and the other parameters were used as a reference.

\subsection{3 $T_{0 n}-T_{\text {off }}$ analysis for silver-copper composite fluids with equal and unequal proportions of silver and copper}

After the parameters of the silver-copper composite fluids with equal and unequal proportions of silver and copper were compared, two optimal parameters (i.e., $10: 10$ and $30: 50$ ) were examined. When the ratio was set as $30: 50$, the value of total mass loss was high and the particles were small, as was the absolute value of the zeta potential. For the fabrication of the silver-copper nanocomposite metal materials, the optimal ratio was $30: 50$.

\subsection{Using the capacitor charging method to improve the zeta potential of metal nanoparticles}

The silver-copper nanocomposite metal fluid was left to sit for a long period, until precipitates had formed. After the metal fluid was charged for 7 days, 14 days, 30 days, and 60 days, the Zetasizer nano system was used to observe the zeta potential of the charged fluid and that of the uncharged sample. Figure 10(a) shows the comparison results between the zeta potential of the metal fluid charged for 7 days and that of the uncharged sample. Figure 10(b) displays the comparison results between the zeta potential of the metal fluid charged for 60 days and that of the uncharged sample. The particles were examined to determine whether they were suspended after charging, as shown in Table 6.

As shown in Fig. 10(c), once charged, the nanocomposite fluid had excellent suspension stability because of an increase in the absolute value of the zeta potential. Under an identical 
(a)

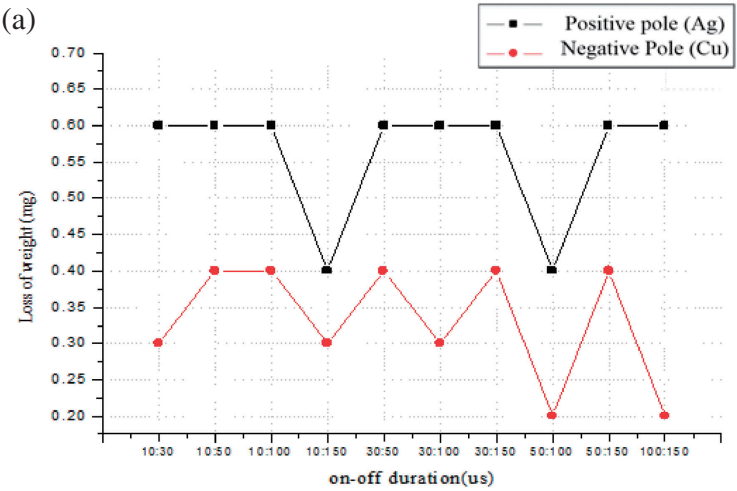

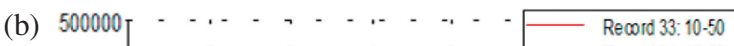
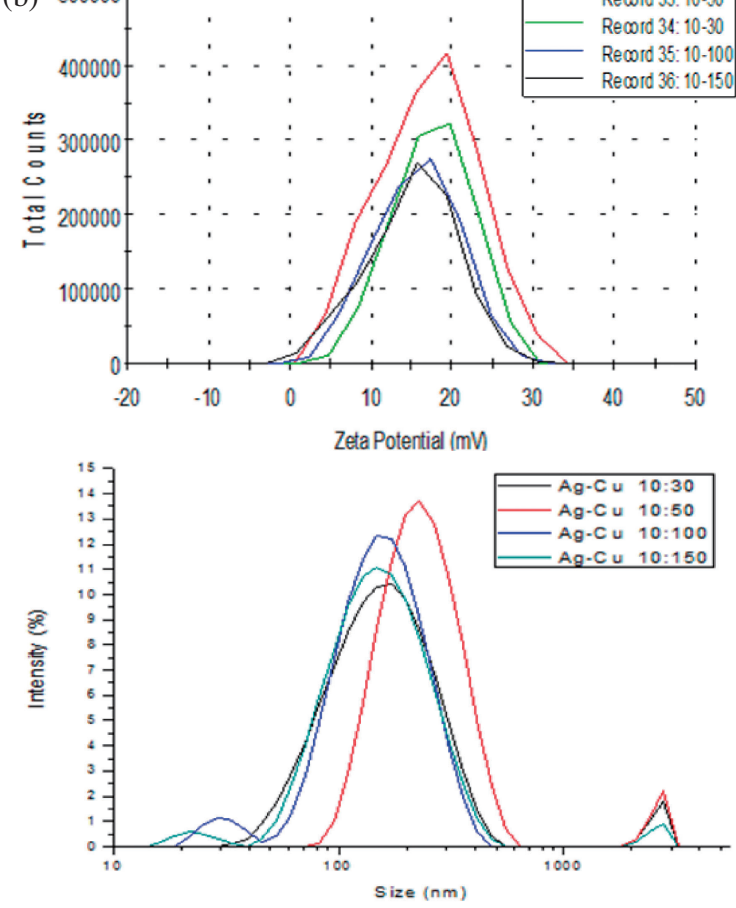

Fig. 9 (a) Mass-loss curve for silver-copper composite fluids with unequal proportions of silver and copper, (b) Particle size and zeta potential $\left(T_{\mathrm{on}}=10 \mu \mathrm{s}\right)$ for various ratios, (c) Particle size and zeta potential $\left(T_{\text {on }}=30 \mu \mathrm{s}\right)$ for various ratios, (d) Particle size and zeta potential $\left(T_{\mathrm{on}}=50 \mu \mathrm{s}\right.$ or $\left.100 \mu \mathrm{s}\right)$ for various ratios.

precipitation duration, in comparison with an uncharged sample, the total number of nanoparticles was large. After 7 days of precipitation, the surface potential of the uncharged fluid was low, with a large number of nanoparticles, and therefore, the total count had decreased substantially. After 2 weeks of precipitation, the total number of charged samples
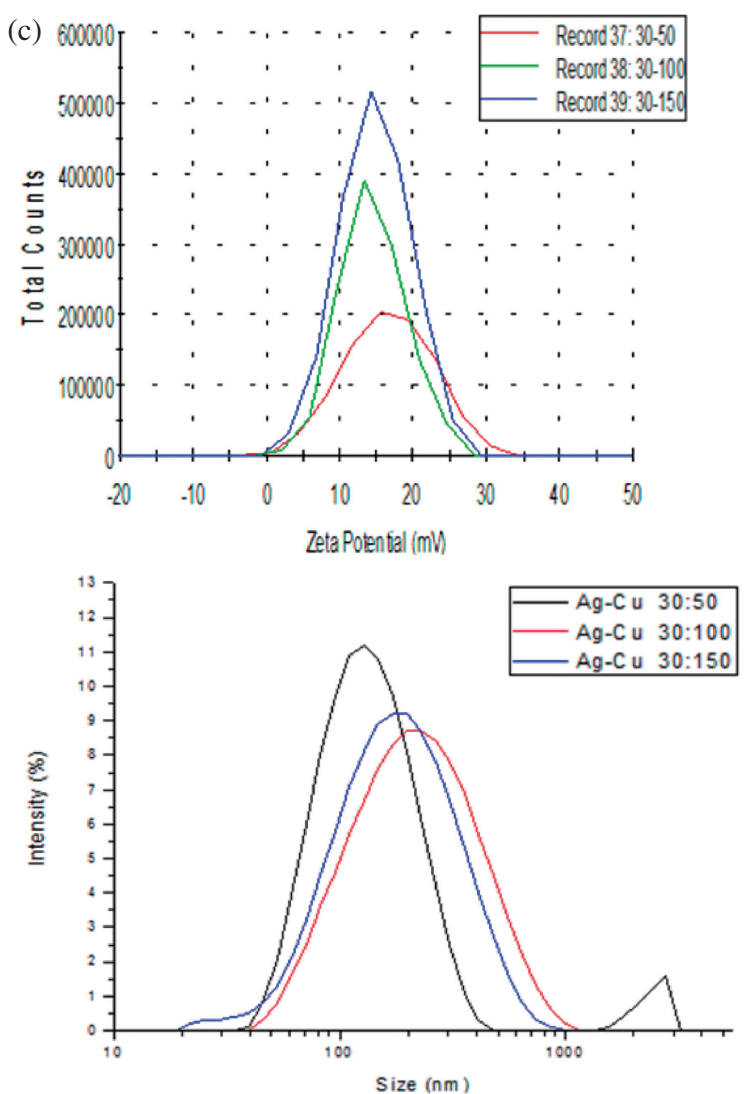

(d)
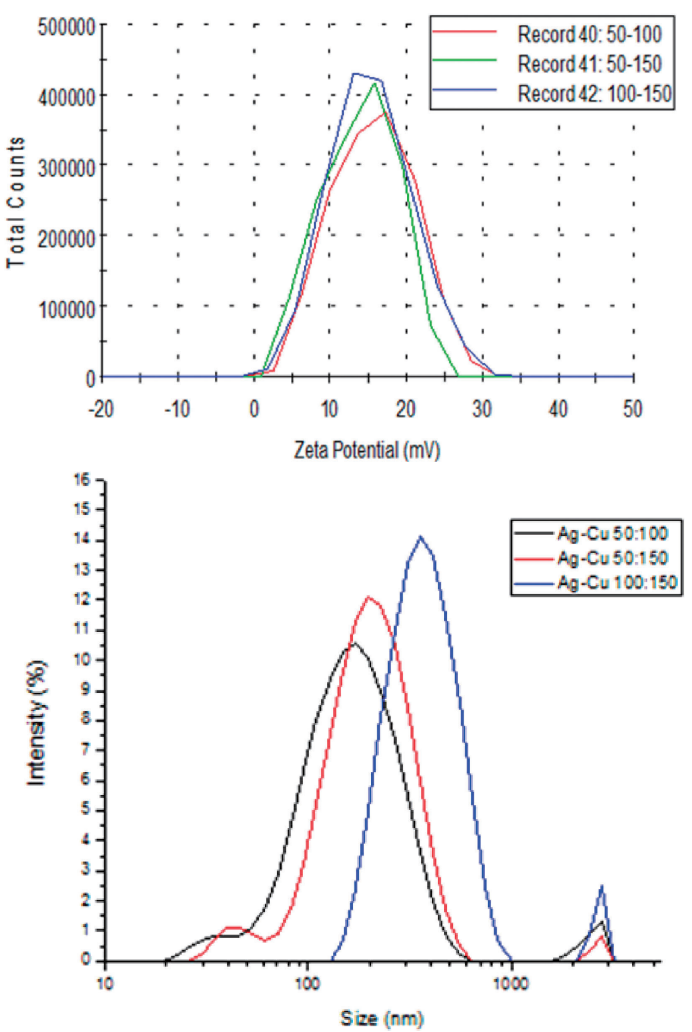

decreased substantially. After 7 to 14 days, the particles discharged, and those with a low surface potential became precipitates, whereas those with a high surface potential remained suspended in the solution. After 30 days, the charged and uncharged samples stabilized, and the total count did not decrease. After 60 days, for the charged samples, 
10(a)-1 precipitated for long time

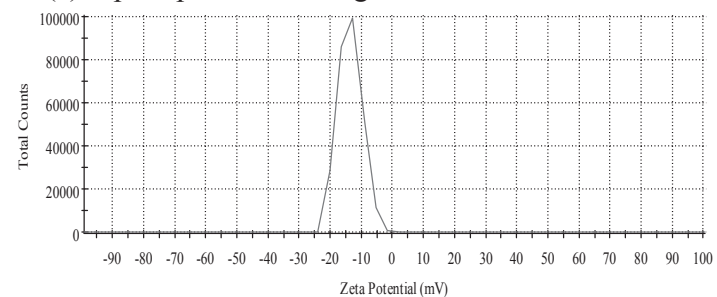

10(a)-2 charged for 7 days

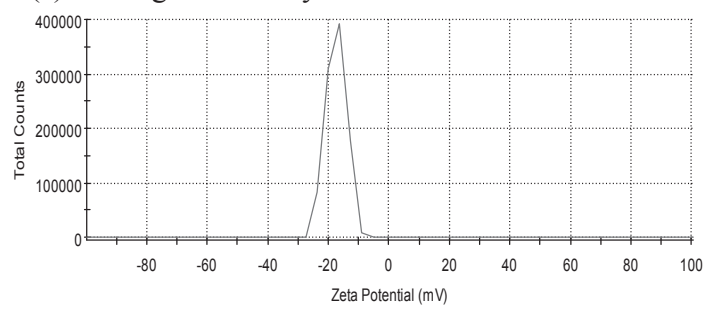

10(b)-1 uncharged for 60 days

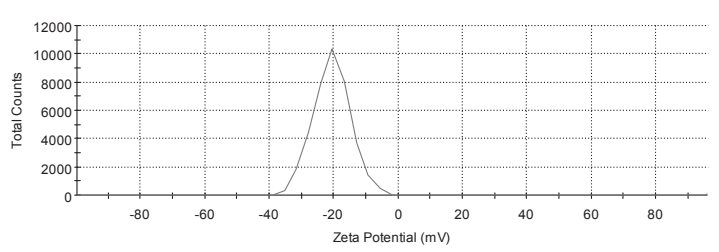

10(b)-2 charged 60 days and precipitated 60 days

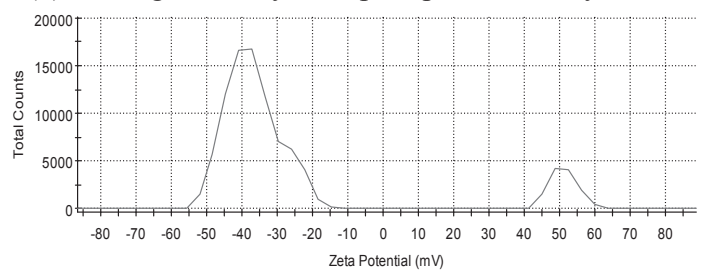

(c)
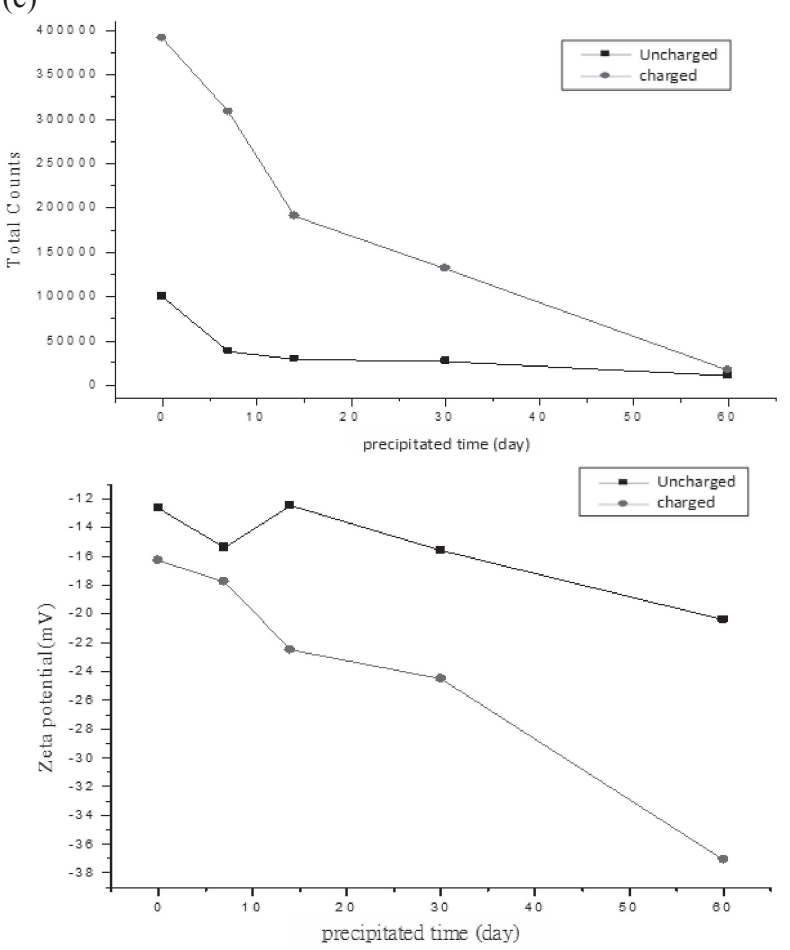

Fig. 10 (a) The zeta potential of uncharged nanofluid and of charged fluid (after 7 days), (b) The zeta potential of uncharged nanofluid and of charged fluid (after 60 days), (c) Total count and zeta-potential curves of charged and uncharged nanocomposite fluids.
Table 6 Amount of time required for precipitation of charged and uncharged nanocomposite fluids.

\begin{tabular}{lllll}
\hline & \multicolumn{2}{c}{ uncharged } & & Sample after 7-days charging \\
\cline { 2 - 3 } \cline { 5 - 6 } & Total counts & $\begin{array}{c}\text { zeta potential } \\
(\mathrm{mV})\end{array}$ & Total counts & $\begin{array}{c}\text { zeta potential } \\
(\mathrm{mV})\end{array}$ \\
\hline $\begin{array}{c}\text { precipitated } \\
\text { for 0 days }\end{array}$ & $99,386.95$ & -12.7 & $391,483.47$ & -16.3 \\
\hline $\begin{array}{c}\text { precipitated } \\
\text { for 7 days }\end{array}$ & $38,049.73$ & -15.4 & $308,199.53$ & -17.8 \\
\hline $\begin{array}{l}\text { precipitated } \\
\text { for 14 days }\end{array}$ & $29,450.84$ & -12.5 & $190,680.00$ & -22.5 \\
\hline $\begin{array}{l}\text { precipitated } \\
\text { for 30 days }\end{array}$ & $26,731.54$ & -15.6 & $131,246.80$ & -24.5 \\
\hline $\begin{array}{l}\text { precipitated } \\
\text { for 60 days }\end{array}$ & $10,324.05$ & -20.4 & $16,710.31$ & -37.1 \\
\hline
\end{tabular}

the surface potential of most of the particles increased substantially.

\section{Conclusions}

The production of silver-copper composite colloidal metal particles combines the fields of motor control and materials science. Developments in nanotechnology lead to higher demand for nanomaterials. Nanofluids were fabricated through ESDM, and were examined using X-ray diffraction, Zetasizer, and SEM. The experimental results are as follows:

(1) In this study, the SADM was employed to fabricate silver-copper nanocomposite metal fluids. The discharging parameters and suspension stability of silvercopper alloys with excellent electrical and thermal conductivity were analyzed. Using the capacitor charging method, the nanoparticles were charged to obtain precipitates in order to improve their interfacial potential and to suspend the nanoparticles in the dielectric fluid. This study examined the characteristics of the nanofluids produced under various $T_{\text {on }}-T_{\text {off }}$ ratios in the composite metals. By setting the parameters to have equal ratios, and by increasing the resting time, the optimal process parameters were determined, and the suspension stability of the charged nanoparticles was investigated.

(2) The SADM was applied to obtain nanocomposite metal fluids at room temperature and $1 \mathrm{~atm}$. The fluid particles were suspended in deionized water without adding chemicals. The metal fluid was produced at a low cost, and with great efficiency and speed. In the future, the demand for nanomaterials will increase. For this study, the mass production of nanomaterials was considered, in addition to environmental protection concerns.

(3) In the experiment, a knob was used for polarity control, thereby permitting changes to the metal mass loss of the positive and negative electrodes as well as to equalize the proportion of silver and copper in the produced fluid. SEM was employed to photograph the nanocomposite metal particles, and to show that the 
fabricated fluid contained core-shell alloy particles.

(4) When the SADM was employed, the electrical current (IP) was set to be constant. The discharging parameter was set as $T_{\text {on }} \leqq T_{\text {off }}$, and the material removal rate, particle size, and surface potential of the composite metal were examined. The results revealed that when the discharging parameter $\left(T_{\text {on }}-T_{\text {off }}\right)=30: 50$, nanocomposite fluids with an optimal concentration containing small particles could be obtained.

(5) Because the composite nanoparticles became precipitates easily, the capacitor charging method was used to charge the precipitated composite metal nanoparticles. The experimental results revealed that the charged particles became suspended after gaining in potential. In addition, the suspension stability of the charged particles was excellent.

\section{REFERENCES}

1) A. Sarkar, T. Mukherjee and S. Kapoor: J. Phys. Chem. C 112 (2008) 3334-3340.

2) B. C. Ranu, A. Saha and R. Jana: Adv. Synth. Catal. 349 (2007) 26902696.

3) E. K. Athanassiou, R. N. Grass and W. J. Stark: Nanotechnology 17 (2006) 1668.

4) Y. Leroux, J. C. Lacroix, C. Fave, G. Trippe, N. Felidj, J. Aubard, A. Hohenau and J. R. Krenn: ACS Nano 2 (2008) 728-732.

5) N. Cioffi, L. Torsi, N. Ditaranto, G. Tantillo, L. Ghibelli, L. Sabbatini, T. B. Zacheo, M. D. Alessio, P. G. Zambonin and E. Traversa: Chem. Mater. 17 (2005) 5255-5262.

6) X. Zhang, G. Wang, X. Liu, H. Wu and B. Fang: Cryst. Growth Des. 8 (2008) 1430-1434.

7) P. S. Ghosh, C. K. Kim, G. Han, N. S. Forbes and V. M. Rotello: ACS Nano 2 (2008) 2213-2218.
8) B. K. Park, D. Kim, S. Jeong, J. Moon and J. S. Kim: Thin Solid Films 515 (2007) 7706-7711.

9) N. A. Luechinger, E. K. Athanassiou and W. J. Stark: Nanotechnology 19 (2008) 445201.

10) Y. Lee, J. Choi, K. J. Lee, N. E. Stott and D. Kim: Nanotechnology 19 (2008) 415604.

11) N. Toshima and Y. Wang: Langmuir 10 (1994) 4574-4580.

12) N. Toshima and Y. Wang: Adv. Mater. 6 (1994) 245.

13) S. Link, Z. L. Wang and M. A. El-Sayed: J. Mater. Chem. B 103 (1999) 3529 .

14) K. C. Grabar, R. G. Freeman, M. B. Hommer and M. J. Natan: Anal. Chem. 67 (1995) 735-743.

15) Y. Mizukoshi, K. Okitsu, Y. Maeda, T. A. Yamamoto, R. Oshima and Y. Nagata: J. Phys. Chem. 101 (1997) 7033-7037.

16) S. Remita, M. Mostafavi and M. O. Delcourt: Radiat. Phys. Chem. 47 (1996) 275-279.

17) D. H. Chen and C. J. Chen: J. Mater. Chem. 12 (2002) 1557-1562.

18) Y.-H. Chen and C.-S. Yeh: Chem. Commun. 2001 (2001) 371-372.

19) I. Lee, S. W. Han and K. Kim: Chem. Commun. 2001 (2001) 17821783 .

20) T. Nakamura, Y. Tsukahara, T. Yamauchi, T. Sakata, H. Mori and Y. Wada: Chem. Lett. 36 (2007) 154-155.

21) K. Esumi, M. Wakabayashi and K. Torigoe: Colloids Surf. A 109 (1996) 55-62.

22) M. Michaelis, A. Henglein and P. Mulvaney: J. Phys. Chem. 98 (1994) 6212-6215.

23) D.-C. Tien, C.-Y. Liao, J.-C. Huang, K.-H. Tseng, J.-K. Lung and T.-T. Tsung: Rev. Adv. Mater. Sci. 18 (2008) 750-756.

24) K.-H. Tseng and J.-C. Huang: J. Nanopart. Res. 13 (2011) 2963-2972.

25) K.-H. Tseng, J.-C. Huang, K.-C. Chen and C.-Y. Liao: The 6th IEEE Conference on Industrial Electronics and Application, (2011) pp. 2711-2716.

26) C.-Y. Liao, K.-H. Tseng and H.-S. Lin: Metall. Mater. Trans. B 44 (2013) 91-97.

27) K.-H. Tseng, J.-L. Chiu, H.-L. Lee, C.-Y. Liao, H.-S. Lin and Y.-S. Kao: Adv. Mater. Sci. Eng. 2015 (2015) 1-10.

28) P. T. Eubank, M. R. Patel, M. A. Barrufet and B. Bozkurt: J. Appl. Phys. 73 (1993) 7900-7909. 